\title{
The Morality of Everyday Activities: Not the Right, But the Good Thing To Do Daniel Nyberg
}

\begin{abstract}
This article attempts to understand and develop the morality of everyday activities in organizations. Aristotle's concept of phronesis, practical wisdom, is utilized to describe the morality of the everyday work activities at two call centres of an Australian insurance company. The ethnographic data suggests that ethical judgements at the lower level of the organization are practical rather than theoretical; emergent rather than static; ambiguous rather than clear-cut; and particular rather than universal. Ethical codes are of limited value here and it is argued that by developing phronesis members of the organization can improve their capacity to deal with this ethical complexity.
\end{abstract}

KEY WORDS: aristotle, ethical codes, organizational ethics, phronesis, situated ethics

\section{Introduction}

Our present inquiry is (unlike our others) not aimed at theoretical knowledge. We are not conducting our inquiry in order to know the definition of virtue, but in order to become good, otherwise it would not benefit us at all. So we must think about what concerns actions and how we ought to perform them...(Aristotle cited in Hughes, 2001: 13)

There is a growing focus on business ethics in the aftermath of recent corporate scandals. The main response from the business community has been to develop ethical codes or rules for members of organizations to follow (Clegg et al., 2006; Cummings, 2002; Stevens, 2004). In the quotation above, Aristotle points out the limitations of ostensive definitions and codes of ethics in increasing morality in organizations. Aristotle redirects our attention away from codes of ethics and towards the situated activities where ethical choices are actually made. This article aims to further develop an understanding of the morality of everyday activities by illustrating the ambiguity of ethics, and to advance the notion of practical and situated ethics to further enhance ethical activities in organizations. The practical accomplishment of organizational life is shown to be ambiguous and it is not clear when ethical reasoning is being applied (Trevino and Brown, 2004). The normal problems workers and managers deal with in doing their jobs are not major ethical dilemmas or ethical policy-making, but rather routine tasks and everyday work practices (Alvesson and Svenningsson, 2003). It is in these mundane everyday activities that an ethical discussion needs to begin in order to avoid ethical dilemmas and to develop practical ethical awareness (Clegg et al., 2006). This calls for a situated and practical concept of ethics to describe empirically the morality of work activities, how activities become im/moral, and how morality can be increased in everyday organizational practices. In the Nicomachean Ethics, Aristotle (350 B.C./1999) discusses an intellectual virtue based on practical wisdom, phronesis, which is an appropriate candidate for the pursuit of ethics in practice (MacIntyre, 1981; Tsoukas and Cummings, 1997).

Arguably, traditional ethical theories (consequentialism and deontology) are not suitable for this project, since universal principles and rules leave little room for the ambiguity and everydayness of situated work activities. Traditional ethical theories are primarily concerned with evaluating ethical reasoning based on the outcome of their consequences according to utilitarianism; or, deontological moral rules based on duty, rights and justice. While coming from diverse intellectual traditions, what these ethical theories have in common is that acting ethically is concerned with following rules based on: (a) the benefit and 
harm of the action (utilitarian); (b) whether the principle of the action can become a universal law (duty); (c) whether the action respects human and natural rights (rights); or (d) whether the procedure and outcome of the action is fair (justice). This article does not argue against these theoretical traditions and it is not opposed to ethical rules and principles. On the contrary, ongoing theoretical discussions are beneficial to moral training and reflection. Rather the problems are (1) the universalistic claim that the codes or principles of ethics extracted from these theories can be used to evaluate and promote ethical behaviour in any given situation and organization (Bauman, 1993); and (2) the belief that following these theories will lead to the ethically right act, which means that we can use them to evade our responsibilities for our own actions. Although we can be guided by ethical theories, we need to be aware that narrow and precise theoretical principles of "right" and "wrong" are forced upon broad organizational practice, which has a complexity that the moral theories cannot capture (Maguire, 1997). The principles and rules often appear to be indifferent to the position and situation from which any business decision is taken, which makes them idealistic rather than pragmatic (Solomon, 1992). These theories are arguably more applicable to theoretically defined situations and problems or quests for universally true or right actions, than problems we encounter in practice.

It is important to discuss the limitations of ethical codes, since developing them is the conventional approach to dealing with business ethics in organizations (Clegg et al., 2006; Cummings, 2002; Kjonstad and Willmott, 1995; Munro, 1997; Murphy, 1995; Stevens, 2004). It is even plausible to suggest that ethical rules and codes can have the opposite effect from what is intended. Developing ethical codes can be a way for corporations to pay lip service to the surrounding community. It has been argued that larger firms have ethical codes, but they are commonly used for their symbolic value in satisfying stakeholders and improving the corporate image (Kjonstad and Willmott, 1995; Munro, 1997; Stevens et al., 2005). This implies that if no one is "watching" the corporations would not implement the codes, which makes profit (not ethics) the purpose of having codes and so they do not add anything beyond the economic logic of the organizations (Cummings, 2002). The huge gulf between having ethical codes and actually following them is convincingly illustrated by Enron, a company with an extensive ethical code (Stevens, 2004). Furthermore, adherence to ethical codes or rules can limit ethical awareness, since ethical codes can lull people into the false belief that as long as they follow the code, they are acting ethically (McCracken et al., 1998). It is symptomatic of this that most ethical codes are concerned with protecting the company from legal action and fines, rather than providing guidance for acting ethically (Murphy, 1995; Stevens, 1994, 2004; Vogel, 1992). This is not surprising, since ethical codes or rules cannot deal with the ethical complexity and ambiguity of many situations. If the situation were straightforward, one would arguably not require ethical reasoning in the first place. Finally, there is a paradox in being forced to comply with ethical codes or rules and claiming to act ethically. Aristotle (1999) suggests that actions need to be voluntary to be ethical.

To complement and make better use of ethical codes in organizations, this article continues by first drawing upon Aristotle's Nicomachean Ethics to understand the morality of situated activities. It argues that Aristotle's concept of phronesis is useful to highlight both ethical and political considerations of practitioners and their activities. Second, the case material, two call centres of a medium-sized Australian insurance company, is outlined together with the research methodology. The empirical illustrations are based on 8 months of mainly observational fieldwork to describe practical performance as it happens in context. Third, the findings are analysed and presented separately for the two call centres, Business Relations and Support Centre, to situate the discussion of phronesis empirically. The extracts from the Business Relations call centre illustrate how phronesis is learnt through collaborative experience and questioning the work rules. The observations from the Support Centre illustrate how different situated pressures drain individuals from phronesis and allow ethics to slip. It is finally concluded that the development of phronesis can empower employees to undertake morally appropriate activities. The advantages of a phronesis-based approach to ethics are outlined through comparison with more conventional approaches in business ethics. Through this comparison, the article makes empirical 
and theoretical contributions to understanding the practical development of morality and ethical reflections in everyday activities.

\section{Phronesis: practical wisdom}

In the Nicomachean Ethics, Aristotle (1999) outlines three classes of intellectual virtue: Episteme, Techne and Phronesis. Episteme (scientific knowledge) can be likened to the concept of ethics based on rules and principles of how to act (consequentialism and deontology). Techne (craft knowledge) is concerned with the skills and know-how of craft and production. This article will discuss the third, Phronesis (practical wisdom), which is "concerned with action about things that are good or bad for a human being" (Aristotle, 1999: 89). The ethical component makes phronesis the highest intellectual virtue above and beyond the other two. Phronesis is not the "right" way of doing things in a particular community, but the ethically good action a practical wise person would take. Although practical, techne differs from phronesis in that the means of production are for the sake of products, while phronesis has it end in itself, that is, acting with practical wisdom (Aristotle, 1999). To understand a practically wise action, it would not be enough to look at the end product or the consequence of what a person did; we need to see how and why the person did what $\mathrm{s} /$ he did in that particular situation (Bragues, 2006). Ethical evaluations need to be situated and contextualized. Phronesis is the ability to act well in specific situations (Aristotle, 1999). By putting practice in the foreground, phronesis closely connects ethics and actions in situated circumstances, "since [phronesis] is concerned with action and action is about particulars" (Aristotle, 1999: 92).

Aristotle (1999) questions the usefulness of knowledge, which is not connected to actions by arguing that you only become good by doing good. The emptiness of knowledge and the impossibility of becoming good without actions are illustrated by the example of a patient not following a doctor's advice:

The many, however, do not do these [virtuous] actions. They take refuge in arguments, thinking that they are doing philosophy, and that this is the way to become excellent people. They are like a sick person who listens attentively to the doctor, but acts on none of his (sic) instructions. Such a course of treatment will not improve the state of the sick person's body; nor will the many improve the state of their souls by this attitude to philosophy. (Aristotle, 1999: 22)

For Aristotle, the virtue of a person is in their customary actions: "Virtue of character results from habit [ethos]; hence its name 'ethical', slightly varied from "ethos", (Aristotle, 1999: 18). Virtue is intrinsic to the human being and comes naturally without application of ethical rules. The habitual act does not make it thoughtless, since a virtuous person takes the right action in each particular circumstance knowing that it is the right action. The reason and desire of the action is in it, not causing it. The good action cannot be described independently of the situation in which it is performed, or generalized into universal laws or rules, since that would separate knowledge from actions and the rule from the contextual circumstances. Again using a doctor and the practice of medicine to make the point, Aristotle argues for the particular situation in which the virtuous action occurs:

For what the doctor appears to consider is not even health [universally, let alone good universally], but human health, and presumably the health of this human being even more, since he (sic) treats one particular patient at a time. (Aristotle, 1999: 7)

A good doctor knows how to treat each particular patient based on general knowledge of medicine, but, more importantly, on practical experience of actually treating patients (Morse, 1999). Consequently, ethics must focus on activities in a particular situation, since no patient or situation is the same. Aristotle does not believe that there can be generally applicable ethical rules and he offers no decisional procedure, since the circumstances always change. Furthermore, if we are forced to obey rules, the actions are not virtuous, because a precondition for virtue is that the action is voluntary (Aristotle, 1999). Consequently, with an increase in external pressures we have a simultaneous decrease in possible virtuous actions. These actions can still have a good cause or consequence, but they would not be virtuous.

Ethical considerations cannot be pinned down to certain principles, since we ought to behave differently in different situations. In practice, ethical decision- 
making always takes place in particular circumstances (Morse, 1999). The goodness of the action is in it, without any separation of the act and the deliberation leading up to it. Aristotle's concept of phronesis can therefore be seen as bridging the mind/body dualism, since the habit of virtue is the habit of thought and action. Phronesis is about doing "the right thing, in the right way, and at the right time" (Aristotle, 1999: 94). It is concerned with making good judgements in ambiguous everyday situations. We need to situate ethics empirically in our everyday practical coping whenever ethical decisions and choices appear. Arguing against universalism, but for holism, Aristotle recognized that virtuous activities are necessarily embedded in a community, polis, and that the evaluation is not based on a single act, but on the agent's virtue. In evaluating agent's behaviour, the totality of both the individual and the practical situation must be considered. We move from the universal question of "what $\mathrm{N}$ should do relative to a certain consideration" to the situated question of "what $\mathrm{N}$ should do all things considered". Only the second question is likely to occur in practice and the good action, according to Aristotle (1999), would be the action that a practically wise agent, phronimos, would take in that situation.

There is an interesting tension in Aristotle's ethics between the virtue of actions and the kind of community an individual takes these actions in, since phronesis is learned first and foremost from the polis. It is the polis that situates phronesis socially and shapes it politically. It is in the performance of activities in a specific community that morality is displayed and can be ethically scrutinized. An Aristotelian approach to ethics thus naturally incorporates politics (Nielsen, 1998), which is suitable for the social and political corporate existence. This also makes the concept of phronesis useful for analysing and developing situated work activities from an ethical perspective. The polis, in our case a mediumsized insurance company, nurtures individual actions with its practices. Phronesis cannot be separated from the position and situation in which the activities are embedded. From an Aristotelian approach, all our thinking and acting is dependent on the idea that we are part of established and ongoing practices, not a separate atomistic individual (Solomon, 2004). In the practical wise act and deliberation, the individual and society are connected. The organizational member is embedded and acts in a particular polis, which both limits and extends the individual's ethical capacity.

\section{Research settings and methods}

This article is based on a qualitative empirical study undertaken in a single organization in order to explore moral actions and ethical reflections in their contexts (Kjonstad and Willmott, 1995). An in-depth case study is suitable if you are interested in practical and context-dependent knowledge to advance our understanding of situated and practical ethics (Flyvbjerg, 2001; Maguire, 1997). The organization, ACNE (a pseudonym), was a medium-sized insurance company with 23 branches and 1,700 employees in Australia. Its main product was car insurance, followed by other types of insurance (house, business, farm, boat, motorbike and caravan) and services (financial services, roadside assistance and home security). The empirical data discussed in this article was collected at two different call centres operated by ACNE, Business Relations and Support Centre, which both handled service calls using mainly script-based performance. Call centres have a reputation in the business community of using enhanced Tayloristic techniques to control their employees. The consultants in the two centres were strictly guided by their computer screens in providing service to customers. There are interesting social and technological dimensions to the morality of performing customer service in a tightly controlled and ruled-based environment.

Although similar in terms of technology and control, the two departments had distinct tasks. Business Relations handled questions, feedback and complaints from internal and external customers. Internal calls involved helping other departments in ACNE by amending specific details of an insurance policy, for example, when a customer moved to another state, had been charged too much or was granted discounts. External calls were about resolving a variety of problems for unsatisfied customers, for example, complaints about the service received, disputes about the claim process, or the amount of money awarded. Business Relations had one manager who supervised two team leaders, each of whom had a team of eight employees. The manager and the team leaders had supervisory positions and did not 
take calls. Support Centre took service calls from customers who had problems and required roadside assistance or assistance in their home. For example, if the customer's car broke down, the operators in the Support Centre made sure that someone assisted the customer to change their car battery, tow the car, or to repair it at the breakdown location. The consultants also arranged other customer care services, depending on the insurance product the customer had, such as getting them a taxi, a rental car, or accommodation where the car broke down. There were two team leaders for each team of 27 employees. The team members could approach either with enquiries during the day. The two-team leaders, who had a supervisory and coaching role, reported to the Support Centre manager.

The main method of data collection was observations to describe, document and understand the activities in their natural spatial and temporal environment (Alexander, 2005; Esterberg, 2002; Silverman, 2001; Yin, 2003). The extended observations were conducted weekly in and around the two departments for 8 months. I took an indirect role in the organization by participating in lunches, tea breaks, informal discussions, and meetings but I did not have any sort of work role at ACNE. Most of the observations took the form of following one frontline consultant through their day at work. I had my own headset, which meant that I could listen to the calls. I took extensive notes during my observations. The "shadowing" were complemented with interviews and textual examinations. Unstructured informal interviews were conducted in the field to explore information about data already observed (Fontana and Frey, 2003). The members of the organization were encouraged to talk to me during the observations, but I rarely asked specific questions and I tried to have neutral responses to the information they provided. The unstructured in-field questions were aimed at understanding how and why the consultant acted in a particular situation. Examples of these open-ended questions were: "What are you doing now?" and "Why are you doing that?"

My initial observations were descriptive and made from a bottom-up approach (Angrosino and Mays de Pérez, 2003; LeCompte and Schensul, 1999). I took little for granted in an attempt to map out what was done repeatedly in the organization, which it involved, in what place, using what equipment. During the longitudinal field study it was then possible to connect actors, activities, equipment and settings into practices, consisting of frequent and similar activities by certain actors using specific tools in particular settings (Lofland and Lofland, 1995). The practice around which this article is built was the most frequent and extensively performed practice of giving service to customers in each department. The consultants in the two departments spent approximately $70 \%$ of their time (including breaks) on customer service. After mapping out the main practice of taking customer service calls, my more focused observations studied how customer service was done in each department. For example, how the members routinely acted when facing a problem in communication with a customer. It was then possible to compare how practice varied internally (within the call centre); externally (between different departments); and from described or prescribed practices (by management, according to training manuals or job descriptions). The analytical focusing and refocusing consequently emerged in three intertwined sequences: (1) mapping what was done in the different communities, that is, the social and repeated practices; (2) mapping how it was normally done in an attempt to find out how and when it was done differently and (3) analyzing the circumstances of deviant cases to understand the morality of these performances to facilitate an ethical discussion.

The findings for the two call centres are presented and discussed separately in order to situate the discussion in the context of the empirical data. Accepted everyday activities and practices in the call centres were often so embedded and pervasive that it was difficult to theorize about them. During the observations, it became clear that in the day-to-day organizational activities, there were rarely any clearcut ethical dilemmas and everyday practice is best described as morally ambiguous. However, it is by attending to everyday activities that major ethical dilemmas can be avoided by "nipping them in the bud" and not allowing morally ambiguous activities to develop into ethical scandals. The numbered extracts from the field notes describe everyday life on the shop floor of the organization. All names are pseudonyms to protect the organization, call centres, consultants and team leaders. 


\section{Business relations: phronesis and decisions that bite}

The cubicles in Business Relations were shoulder high when sitting down, which meant that people could see each other's faces. There were constant interactions between the consultants and a buzz of communication, even though the computer screen in front of each individual consultant by and large determined the outcome of the calls. Interactions and collaborations were not only from their desks. Members of the two Business Relations teams walked around and talked to each other about different issues and problems. The consultants often sat down at each other's desks to discuss how to solve problems. To initiate these kinds of interactions, the person simply shouted the other person's name. This supports Tsoukas and Vladimirou's (2001) observations in a similar workplace environment in Greece, where consultants frequently consulted one another to perform customer service. It was through collaboration that the employees learned how to perform customer service. The consultants rarely asked team leaders for advice and they developed a sense that they were in charge and able to take decisions. This sense of empowerment was supported by the centre manager and the team leaders, who told the consultants to question the rules of the script-based work. The following extract illustrates how the consultants interacted to take an everyday decision to break the rule provided by the computer screen. The rule imposed by the computer program assumes that the driver and the insured person are the same.

\section{Extract 1: Driving Miss Daisy}

An 85 year-old lady has a car, but no driving license. Her husband, who died 10 years ago, used to drive the car. The kids now drive her around in her car. Lauren asks Amy about how to insure the customer's car. After a short discussion with Amy, Lauren goes around the "system" by putting the lady as a qualified driver, even though she is not. This is based on the assumption that the old lady will not drive anyway. In the case notes Lauren writes: "confirmed with Amy".

Lauren: "Our business is not cut and dry, so it is always good to have someone else's opinion. The answer to this query could have been 'no'."'
Lauren continues: "We all know a bit about each other's customers. The decisions can come back and bite us". (Business Relations, 2005-05-11)

Lauren, in the extract above, took an ethical decision to help the elderly lady by insuring her car, even though the computer did not allow this. In collaboration with Amy, Lauren improvised and willingly circumvented not only the programmed computer screen but also the rules on how to insure customers. The old lady is now insured no matter who drives her car. Lauren's decision was not the "right" decision, according to the standardized rules of ACNE, but arguably the morally "good" decision in helping the customer. In their discussion, the consultants only expressed concern about the lady's well-being and did not consider sales figures or "getting rid" of a problem. This decision could not become a moral rule, since on the next occasion it may be a driver with other reasons for not being able to drive the car. It would be less ethical, for example, to support a person who had lost her/his licence for serial drunk driving offences and insure him/her as a "qualified driver", although, there may be circumstances where this actually would be the morally good thing to do. It soon became clear that rules cannot cover all areas and that the good action cannot be planned beforehand. It was in breaking the rule that Lauren made a practical ethical judgement in the extract above. This was done in collaboration with another team member to ensure that the decision did not come back and "bite" her. It was by sharing stories of different situations and decisions that the consultants developed their capacity to deal with different situations (Orr, 1996). By connecting past examples to current situations, the consultants could then reflect upon the situations and develop phronesis (Cummings, 2002).

Phronesis required greater moral sensitivity than the rule-based ethical theories (Dunne, 1993), since it was important for the consultants to be alert to each particular case. The consultants needed to be alert to when the script-based rules on the computer screen were applicable and when they should be questioned and discussed. The script-based rules could still be productive and there was no evident opposition between the "technical" rationality of computers 
and the moral judgements of practical wise consultants (Smith, 1999). The computer-based rules and procedures gave the consultants reflective space for phronesis to question and challenge the rules. This could lead to more appropriate rules upon which the consultants could take even better decisions by freeing time for practical deliberation in other situations. Phronesis is about knowing when the general rules are to be followed, but phronimos will also know when and why to deviate from those rules.

Scope for questioning the rules also gives people scope to not follow the accepted practices when they should have done, which means that reflective space in performance is also space for practical slippage. Lauren mentioned, in the extract above, that decisions could come back and "bite" the consultants. The following extract illustrates a situation where Lauren got bitten:

\section{Extract 2: Files that bite}

Irene is handling a file previously worked on by Lauren, in which Lauren wrote off a policy. Irene looks at the file and then turns around to Lauren in the cubicle behind her and asks her: "Can you please come over for a second?" Lauren walks over to Irene's desk and immediately recognizes the policy on Irene's computer screen. In discussing the file with Irene, Lauren says: "I did a dodgy job. I should have investigated it. Instead I just wrote it off." They agree upon the right action together and the incident is not reported to team leaders or the manager. (Business Relations, 2005-10-14)

In the extract above, Lauren had made an error in a file and it was subsequently picked up by Irene. Lauren did not remember why she did a "dodgy" job, but recognized the work she did as dodgy and that it was not the proper thing to do. Her judgement had slipped in practice and this had monetary consequences for the customer. However, the tight collaboration in Business Relations worked as a "safety net" for the consultants, as they relied on other team members to cover their backs if they uncovered an error at a later date. This safety net was not only used to protect the customers but also fellow team members. The consultants could allow their services to "slip" without any consequences, as long as there was a high level of cooperation among colleagues. This cooperation made sure that some of the slippage was corrected, but also that the slippage was not reported to team leaders or managers. The slippage in this case was picked up by a team member, discussed between colleagues and corrected. Like the discussion regarding the old lady in extract 1 , the new judgement in extract 2 was made through practical collaboration; they took the alternative action together. They experienced a particular situation in practice, which may prevent these two consultants performing a "dodgy" job or making an unethical decision in similar situations at a later date. This illustrates how phronesis is learned through doing. It was through experience, collaboration and discussion that the consultants learned to take morally appropriate practical decisions. Without ethical rules to follow, the consultants were left to gain phronesis by muddling their way through various problems and situations (Maguire, 1997).

\section{Support centre: following rules and timing ethics}

There was not as much collaboration in the Support Centre as in Business Relations. Most of the consultants asked team leaders rather than team members for advice when facing a problem. Interactions between team members occurred but not with the frequency found in Business Relations. The cubicles were higher and the consultants mostly had their backs to each other as they worked. The consultants in the Support Centre rarely left their desks and they did not question the scripts and the ordering of calls presented to them by the computer system. The extract below from the Support Centre illustrates the response from the consultants in the Support Centre to a specific service request when a customer had locked his keys in his car.

Extract 3: Children or animals?

Andrea is on the phone to a customer who has locked his keys in the car. To this Andrea promptly asks: "Do you have any children or animals in the car?" The customer does not, and Andrea proceeds with the call, checking his details and location. She tells him that it will take about $60 \mathrm{~min}$ before a service car will be able to help him. According to Andrea, Chloe and Victoria, all the 
operators ask if there are any children or animals in the car when responding to a customer who has locked their keys in the car. If there are, the nearest patrol immediately interrupts their current work and goes straight to the car to get the children or animals out. If a patrol car unexpectedly discovers children or animals in a car, the operators get verbally reprimanded for neglecting to clarify the issue with the customer. (Support Centre, 2005-08-15)

The Support Centre displayed a duty of care (Gilligan, 1982) towards its customers by making sure that children or animals are taken care of first, even though this would mean letting more profitable services or customers wait or not be attended to. A more cynical reading would be that ACNE does it to avoid lawsuits. However, when openly asked about the practice, the consultants only expressed concern about possible harm to children and animals. Asking whether there are children or animals in the car was simply a customary practice at the Support Centre, because nowhere in the detailed descriptions of how to handle customers with car problems was it lay down that the operators should ask this question. None of the many prescriptive texts, for example, the computer screen, the call coaching form, training manuals and job description, suggested that the question should be asked. This illustrates that the morality of the practice was in the habitual acts, not in documented codes or principles.

The rule on asking this question in the Support Centre only existed because it had become established practice among the consultants. It was upheld by the consultants and the drivers of the patrol cars. It is conceivable that there could be situations where this question might "slip" and not be asked due to various organizational pressures, as the practice of asking the question did not exist in a political vacuum. In the Support Centre, in contrast with the other departments at ACNE, operators were expected to have an average handling time of less than 2 min per call. The next extract illustrates how this affected the everyday interactions between the consultants and the customers.

\section{Extract 4: Interrupting customers}

Phillip tries to finish the call, but the distressed sounding customer wants further assurance that the service car will find him. Phillip glances at the ticking clock on the screen just turning red from green telling him that the call has lasted more than 2 min. After finally finishing the call, Phillip checks his "Average handling time" (the average time in seconds that the consultants have been talking to customers for each call) and "Availability" (the percentage of their time that is spent taking or waiting for calls) for the day: "If the customer waffles on, you have to interrupt. This is because of your stats". (Support Centre, 2005-06-16)

The importance of the statistics for the consultants in the Support Centre was constantly confirmed by my observations. The statistics also caused a lot of distress for the consultants. Consequently, the habit of asking whether there are children or animals in the car could easily be allowed to slip, due to the time limits and the pressure to process the calls they receive as quickly as possible. This efficiency pressure had not always been part of the working practices at the Support Centre and a long-standing member of staff connected it to the introduction of information and communication technology.

Extract 5: The culture of the Support Centre

Catherine: "The culture used to be more about service than efficiency, but now it is more about efficiency than service. They (managers) used to not care about how long you spent talking to a customer as long as the customer was satisfied". (Support Centre, 2005-09-29)

As a result of compressing the interaction with the customer, the question could "slip" out of practice and not be asked.

Another reason for slippage at ACNE was management circulation. Team leaders from other parts of ACNE coached calls in the Support Centre even though they had never themselves been exposed to or put into practice the rule of asking whether there are children or animals in the car. The following extracts illustrate concerns by both team leaders and consultants in the Support Centre about this practice.

Extract 6: The crucified team leader

Tricia, a team leader, says that ACNE wants all the different team leaders to be able to coach and lead all the different areas. This means that team leaders from other departments within ACNE should be able to coach in the Support Centre. Tricia: "Rose (team leader 
from another department) came down here and was crucified. In theory, we should be able to coach in all the different areas, but it just doesn't work that way". Andrea responds: "This is all part of that 'multi-skilling", she says with an ironic emphasis on multi-skilling. (Support Centre, 2005-08-09)

The problem with swapping team leaders between departments was also expressed by other consultants. Tom: "When we approached her (team leader from another department) with a problem, she said that she didn't know our procedures and could not help, so we had to ask Tricia (another team leader)". (Support Centre, 2005-09-29)

It was the team leaders that coached the consultants to improve their practice in answering calls. "Call coaching" and socialization into the work by team leaders who had never done this job themselves could provide room for ethical slippage. The standardized call coaching forms did not cover all areas. The forms were designed to evaluate the efficiency of the consultant in terms of greeting the customer in the correct way, reporting the right details, and providing the right answer. The good responses, for example, asking whether there are children or animals in the car, were not included. Not until an accident happens, or the practices are reflected upon by external stakeholders, might the virtue of the practices be considered. However, by then, ethical considerations are often too late. By then, a child or an animal may have been suffocated locked in a car on a hot Australian summer's day. Although disciplinary practices can be both productive and ethical, this manipulation could be replaced by increased awareness of the good thing to do in caring about others. By giving workers time to reflect on their activities and practices, the question of whether or not there are children or animals in the car would probably be asked, not because it is the universal right thing to do, but rather because we can put ourselves in that position, comprehend the despair, and understand that it is the best alternative of the possible actions. This alternative could, of course, resemble the outcomes of ethical theoretical evaluations of the situation, but what is important is to develop practical wisdom to solve problems in the organization, not to develop universal principles that may or may not be applicable in subsequent situations.

Situating ethics in a context highlights the controlling and disciplinary constraints to understanding the situation in which the behaviour occurs as well as how widespread this behaviour is in that particular community. It was evident that the routine practices in each of the call centres were being performed and adjusted to the stresses and strains of the community. Increasing the pressure on the Support Centre staff to end the calls within $2 \mathrm{~min}$, therefore, could lead to the disappearance of the habits of morality, which would then have to be replaced by social or technological control if they were not to be lost. Most instances of ethical slippage could easily be solved socially through more extensive call-coaching, or technologically through another predetermined box to tick or question to ask being programmed into the computer program's interface. However, deskilling the humans and substituting the "unreliable" worker with socially or technologically standardized rules takes us back to a rule-based ethic and its conflation with control. Controlling managerial and technological pressures drain employees of phronesis, since there is no opportunity to use it, and phronesis, like all practical skills, needs practice. This questions the usefulness and morality of prescriptive ethical codes or principles on guiding practical behaviour. This issue has been discussed (Stevens, 1994; Weaver, 1995) and contested (Kjonstad and Willmott, 1995) elsewhere, with the latter more critical perspective arguing that ethical codes or rules are being confused with power mechanisms and organizational control, rather than ethical judgements. Ethical prescriptive rules or codes can therefore be seen as "managerial tools for shaping change" (Stevens, 1994: 64), where "employees then have the option of complying, at least behaviourally, with the code's instructions or risking their livelihood" (Kjonstad and Willmott, 1995: 449). The foundations of the rules are in the power of decision-makers, whose knowledge of the everyday work activities are often limited and whose agendas are not necessarily for the human good.

\section{Conclusions and implications}

The examples above are useful for understanding how ethics can be studied and conceptualized empirically in everyday activities. From these brief examples, it is now possible to sketch out some advantages of considering phronesis in business ethics and the implications of the development of 
practical wisdom, which are summarized in Table I below. The examples and discussion above illustrate how phronesis locates ethics in a particular situation, where the actual choices need to be made. In this rich context, ethics becomes much more ambiguous and codes are of limited use (Munro, 1997). Situated and practical ethics imply immunity to theoretical universalization. This does not mean that we cannot make judgements and that "anything goes" in a relativist sense. On the contrary, these judgements should be considered in the material and social context of limited choices and possibilities for action. We need to realize the emptiness of ethical rules without situated actions; it is in the doing that actions acquire their ethical significance (Holt, 2006; Maguire, 1997). Hence, the identification and evaluation of unethical behaviour should be based on what is done in a specific situation within a particular context, with the aim of ethics being to develop the capacity to handle these situations. In everyday actions, ethics is practical and the development of phronesis can guide one through the particularities. Phronesis is not the "right" way of doing things in a particular community, but the "good" action under the circumstances. Taking the situation into account means that one needs to give employees the best opportunity to act ethically in the community. The examples above illustrate the importance of easing the material and social pressures of the situations. If one wants the organizational members to act ethically, they need to be able to take ethical decisions and to be given scope to reflect upon the decisions.
Phronesis is developed through experience of understanding alternative actions and this experience is gained by sharing situations, cases and stories. It is through experience, collaboration and discussion that members of organizations develop the capacity to take morally appropriate practical decisions. Successful ethical learning occurs in the contingent practical situations that emerge in the workplace. That is why it is in the situations that ethical socialization and training must occur, to make sure that a more ethical community emerges from past practices. Giving people time to reflect upon and discuss their activities does not necessarily change them but it does make change more likely. The alternative is to enforce disciplinary and controlling pressures to make people behave in certain ways. However, rules or principles will not get us there, since we cannot expect people to act ethically if there they are given no opportunity to exercise practical ethical judgement. This is the major point: following ethical codes does not involve choice, merely compliance; if one does not choose to act, one has not acted ethically. Too many codes and regulations, and too much control lead to the opposite, since there will always be situations that the ethics codes cannot cover; where the upgraded computer programs cannot give you the answer; and customer situations that the call-coaching form does not deal with. There are rarely any clear-cut cases when the complexity of organizational life is taken into account. Complex and extensive rules require an even more virtuous user, since rules are only useful if one is allowed to question them.

TABLE I

Comparison between conventional and phronesis-based ethics

\begin{tabular}{|c|c|c|}
\hline & Conventional Business Ethics (deontological, consequential) & Phronesis \\
\hline Aim & Search for universal rules to handle all situations. & $\begin{array}{l}\text { Development of practical wisdom } \\
\text { to handle particular situations. }\end{array}$ \\
\hline Underlying thesis & Right versus wrong reasoning. & Better versus worse actions. \\
\hline Method & Development of rules. & Development of human beings. \\
\hline Moral training & $\begin{array}{l}\text { Theoretical understanding of the ethical } \\
\text { theories and their inherited rules. }\end{array}$ & $\begin{array}{l}\text { Practical understanding of different } \\
\text { alternatives to consider. }\end{array}$ \\
\hline Pedagogy & Memorising rules. & Sharing cases and stories. \\
\hline Usage & Suitable for theoretical dilemmas. & Suitable for practical dilemmas. \\
\hline Advocates & Promotion of compliance with rules. & Promotion of questioning of rules. \\
\hline Consequence & Restricts moral capacity. & Empowers moral capacity. \\
\hline
\end{tabular}


Learning does not necessarily take place through increased analytical interpretation of others' behaviour. We may just do what others do, act without reflecting on what we are doing, and find it difficult to articulate the practical rules that we are following (Tsoukas and Vladimirou, 2001). It is therefore important to raise the situational awareness and understanding of what individuals are doing. Drawing upon the case study, one example would be to raise the awareness of the "informal" rule of asking whether there are children or animals in the car, discuss the implications and morality of the rule, and make sure that new members in the community are aware of the "good" actions above and beyond the "right" ones. However, the mere rule itself would mean very little if it were not for the rich stories surrounding the question and its contextualized consequences. To further develop their practical wisdom, the consultants in the case needed to question the wider tradition of customer service and connect their practices to the surrounding society. Phronesis is about directing our actions towards the good of the whole community (Aristotle, 1999). Tsoukas and Vladimirou suggested this in arguing that "practical mastery needs to be supplemented by a quasi theoretical understanding of what individuals are doing when they exercise that mastery" (2001: 989-990).

Rather than merely promoting ethical codes, we should, like the manager in the Business Relations call centre, recommend that staff question and discuss ethical codes in their everyday activities to develop their phronesis. Disagreement about how to act in the organization should therefore be welcomed, in order to allow the situation to be viewed from different perspectives and to work out alternative actions. Post-modern ethics has taught us that "there are no right views, just a number of perspectives" (Duska, 1993: 235) and pragmatists have taught us that the best alternative in that specific situation should be applied (Rorty, 1999, 2006). Phronesis is about questioning the "right" way of doing things to make sure the "good" way of doing things is performed. Developing phronesis encourages moral activities and practices. To improve morality, ethical reflection must therefore be concerned with the situated performance, rather than universal principles or texts in the form of guidelines or codes of conduct. Phronesis is acquired through critically questioning the written and unwritten rules, principles and codes. Universal ethical codes and rules of "right" and "wrong" are useful as a basis for discussion and reflection, but phronimos needs to know when and why to follow or break rules in practice. By being confronted with complex situations where there are no right answers, the employees learn to make "good judgements in difficult situations" (Maguire, 1997: 1412). Phronesis is about constantly improving oneself to handle different and uncertain situations in life better (Holt, 2006), where there are often multiple and conflicting choices to be made (Clegg et al., 2006). Developing phronesis can empower employees to make choices, take decisions in morally ambiguous situations, and take responsibility for their choices.

\section{References}

Alexander, B. K.: 2005, 'Performance ethnography', In N. K. Denzin and Y. S. Lincoln (eds.), The Sage handbook of qualitative research, 3rd Edition (SAGE, Thousand Oaks).

Alvesson, M. and S. Svenningsson: 2003, 'Managers Doing Leadership: The Extra-Ordinarization of the Mundane', Human Relations 56(12), 1435-1459.

Angrosino, M. V. and K. A. de Mays Pérez: 2003, 'Rethinking Observation: From Method to Context', In N. K. Denzin and Y. S. Lincoln (eds.), Collecting and Interpreting Qualitative Materials (Sage, Thousand Oaks).

Aristotle: 1999, Nicomachean Ethics, T. Irwin, Trans. 2nd Edition (Indianapolis: Hackett).

Bauman, Z.: 1993, Postmodern Ethics (Blackwell, Oxford). Bragues, G.: 2006, 'Seek the Good Life, Not Money: The Aristotelian Approach to Business Ethics', Journal of Business Ethics 67, 341-357.

Clegg, S., M. Kornberger and C. Rhodes: 2006, 'Business Ethics as Practice', British Journal of Management 17, 116.

Cummings, S.: 2002, ReCreating Strategy (Sage, London).

Dunne, J.: 1993, Back to the Rough Ground: 'Phronesis' and 'Techne' in Modern Philosophy and in Aristotle (University of Notre Dame Press, Notre Dame).

Duska, R. F.: 1993, 'Aristotle: A Pre-Modern PostModern? Implications for Business Ethics', Business Ethics Quarterly 3(3), 227-250.

Esterberg, K. G.: 2002, Qualitative Methods in Social Research (McGraw-Hill, Boston). 
Flyvbjerg, B.: 2001, Making Social Science Matter: Why Social Inquiry Fails and How it Can Succeed Again, S. Sampson, Trans (Cambridge University Press, Cambridge).

Fontana, A. and J. H. Frey: 2003, 'The Interview: From Structured Questions To Negotiated Text', In N. K. Denzin and Y. S. Lincoln (eds.), Collecting and Interpreting Qualitative Materials (Sage, Thousand Oaks, CA).

Gilligan, C.: 1982, In a Different Voice: Psychological Theory and Women's Development (Harvard University Press, Cambridge, MA).

Holt, R.: 2006, 'Principals and Practice: Rhetoric and the Moral Character of Managers', Human Relations 59(12), 1659-1680.

Hughes, G. J.: 2001, Aristotle on Ethics (Routledge, London).

Kjonstad, B. and H. Willmott: 1995, 'Business Ethics: Restrictive or Empowering?', Journal of Business Ethics 14(6), 445-464.

LeCompte, M. D. and J. Schensul: 1999, Analyzing and Interpreting Ethnographic Data (AltaMira Press, Walnut Creek, CA).

Lofland, J. and L. H. Lofland: 1995, Analyzing Social Settings, 3rd Edition (Wadsworth Publishing Company, Belmont, CA).

MacIntyre, A.: 1981, After Virtue: A Study in Moral Theory (Duckworth, London).

Maguire, S.: 1997, 'Business Ethics: A Compromise between Politics and Virtue', Journal of Business Ethics 16, 1411-1418.

McCracken, J., W. Martin and B. Shaw: 1998, 'Virtue Ethics and the Parable of the Sadhu', Journal of Business Ethics 17, 25-38.

Morse, J.: 1999, 'Who is the Ethics Expert? The Original Footnote to Plato', Business Ethics Quarterly 9(4), 693697.

Munro, I.: 1997, 'Codes of Ethics: Some Uses and Abuses', In P. W. F. Davies (ed.), Current Issues in Business Ethics (Routledge, London).

Murphy, P. E.: 1995, 'Corporate Ethics Statement: Current Status and Future Prospects', Journal of Business Ethics 14, 727-740.

Nielsen, R. P.: 1998, 'Can Ethical Character be Stimulated and Enabled? An Action-Learning Approach to Teaching and Learning Organization Ethics', Business Ethics Quarterly 8(3), 581-604.

Orr, J.: 1996, Talking about Machines; An Ethnography of a Modern Job (ILR Press, Ithaca, NY).

Rorty, R.: 1999, Philosophy and Social Hope (Penguin Books, London).
Rorty, R.: 2006, 'Philosophy's Role Vis-à-Vis Business Ethics', Business Ethics Quarterly 16(3), 369-380.

Silverman, D.: 2001, Interpreting Qualitative Data (Sage, London).

Smith, R.: 1999, 'Paths of Judgement: The Revival of Practical Wisdom', Educational Philosophy and Theory 31(3), 327-340.

Solomon, R. C.: 1992, 'Corporate Roles, Personal Virtues: An Aristotelean Approach to Business Ethics', Business Ethics Quarterly 2(3), 317-339.

Solomon, R. C.: 2004, 'Aristotle, Ethics and Business Organizations', Organization Studies 25(6), 1021-1043.

Stevens, B.: 1994, 'An Analysis of Corporate Ethical Code Studies: "Where Do We Go From Here?", Journal of Business Ethics 13(1), 63-69.

Stevens, B.: 2004, 'The Ethics of the US Business Executive: A Study of Perceptions', Journal of Business Ethics 54, 163-171.

Stevens, J. M., H. K. Steensma, D. A. Harrison and P. L. Cochran: 2005, 'Symbolic or Substantive Document? The Influence of Ethics Codes on Financial Executives' Decisions', Strategic Management Journal 26, 181195.

Trevino, L. K. and M. E. Brown: 2004, 'Managing to Be Ethical: Debunking Five Business Ethics Myths', Academy of Management Executive 18(2), 69-81.

Tsoukas, H. and S. Cummings: 1997, 'Marginalization and Recovery: The Emergence of Aristotelian Themes in Organization Studies', Organization Studies 18(4), 655-683.

Tsoukas, H. and E. Vladimirou: 2001, 'What is Organizational Knowledge?', Journal of Management Studies 38(7), 973-993.

Vogel, D.: 1992, 'The Globalization of Business Ethics: Why America Remains Distinctive', California Management Review 35(1), 30-49.

Weaver, G. R.: 1995, 'Does Ethics Code Design Matter? Effects of Ethics Code Rationales and Sanctions on Recipients' Justice Perceptions and Content Recall', Journal of Business Ethics 14(5), 367-385.

Yin, R. K.: 2003, Case Study Research: Design and Methods 3rd Edition, Vol. 5 (Sage Publications, Thousand Oaks, CA).

Nijmegen School of Management, Radboud University Nijmegen,

Thomas van Aquinostraat 1, Nijmegen, 6525 GD,

The Netherlands

E-mail:d.nyberg@fm.ru.nl 